\title{
Sensitivity and variance estimators for virtual population analysis and the equilibrium yield per recruit model
}

\author{
Dominique Pelletier
}

IFREMER, BP $n^{\circ} 1019,41^{\prime \prime} 37$. Vantes Cedex, France.

Received June 28, $19^{8} 9$; arcepted October $30,19^{8} 9$.

Abstract

Pelleticr D. Aquat. Lizing Resour., 1990, 3, 1-12.

Fish stock assessment makes widespread use of Virtual Population Analysis (VPA) and long-term cquilibrium prediction models. Although there have been some statistical investigations about the properties of VPA results, apparently there are no complete analyse about predictions statistical and numerical bchaviour. However, management decisions generally rely upon production forecasts. This paper compares stability properties of VPA and the yield per recruit model with regard to various crrors concerning all the input parameters. Robustness is assessed by means of first-order sensitivitics whereas variances are inferred from delta-method estimators. Sensitivity of yicld per recruit appears to be mainly due to terminal mortality rate and age-specific weights, and to a lesser extent, to catches and natural mortality. Mean values of the input parameters were also found to influence the model's behaviour. A complete estimation of variances would require a variance-covariance matrix for weights at age and terminal fishing mortality rates. Sensitivities and variances are complementary in that the first quantify the absolute robustness of the models whereas the second show model robustness in relation to the dimensioned interval of variation of each input parameter. If variances were available for all parameters, yield per recruit estimates could be taken into account for fisheries management decisions.

Keywords : Virtual Population Analysis, yield per recruit, sensitivity, variance estimation, Deltamethod.

Ezaluation des stocks de poisson exploités : estimations de la zariance et de la schsibilité pour l'analyse de population zirtuelle et un modele de rendement par recrue à l'́quilibre.

Résumé

L'analyse de population virtuelle (APV) ainsi que les modèles de prévision à l'ćquilibre sont souvent utilisés pour l'évaluation des stocks de poisson exploités. Bien que plusicurs études statistiques aient ćté entreprises quant aux propriétés des résultats des $A P V$, il semble qu’aucune analysc approfondie du comportement numérique et statistique des modèles prévisionnels n'ait ćté réaliséc. Ces prévisions de production orientent pourtant les décisions de gestion des pécheries. Cet article compare les propriétés respectives des modëles d'APV et de rendement par recrue en ce qui concerne les incertitudes sur les paramètres d'entrée. Les sensibilités du premier ordre permettent d'évaluer la robustesse de chaque modèle tandis que les variances des résultats sont cstimćes gräce à la méthode Delta. Le rendement par recrue apparait essentiellement sensible au coefficient terminal de mortalitć par pèche ct aux poids, et dans une moindre mesure, aux captures et à la mortalité naturclle. Le comportement des modèles dépend ćgalement de la valeur moyenne des paramètres d'entréc. Une estimation complète des variances nécessiterait une matrice de variance-covariance pour les poids aux áges ainsi que pour les mortalités par pêche terminales. Sensibilités et variances sont complémentaires en ce sens que les premières quantifient la robustesse absolue des modëles alors que les sccondes rapportent cette robustesse à l'intervalle dimensionné de variation de chaque paramètre. Si l'on disposait de variances 
pour tous les paramètres d'entrée, les estimations des rendements par recrue ainsi obtenues pourraient ètre prises en comple lors des décisions de gestion des pécheries.

Mots-clés : Analyse de population virtuelle, rendement par recrue, sensibilité, estimation de la variance, méthode Delta.

\section{INTRODUCTION}

Assessment of exploited fish populations requires estimation of stock size and some biological parameters such as population biomass, yield per recruit or catch projections. For this purpose, fisheries management has been using Virtual Population Analysis (VPA) (Gulland, 1965) and other related methods for more than 20 ycars. VPA results, i.e. stock size and fishing mortality estimates, were considered error-free for a long time and in many cases the uncertain nature of these results is still ignored. However, sensitivity of the models and propagation of errors in parameters have been investigated in several studies.

After introduction of an approximation of VPA called Cohort Analysis, Pope (1972) analysed the consequences of errors in estimations of terminal mortality rate and catches. Later, Saila et al. (1985) extended the study to all input parameters. But these works dealt with Cohort Analysis, which is an approximation of VPA. Furthermore, the problem of simultaneous errors and covariances between input parameters was not discussed. Sampson (1987) took the true VPA into account and these latter hypotheses which were more similar to real data sets. The author estimated the coefficients of variation for VPA results. However, no estimations of catch-at-age variances were used. Sampson (1988) also assessed the inlluence of the input parameters relative mean values onto the stability of cohort size estimates. The cited studies concerncd a single cohort, but fisheries management usually considers a historical series of cohorts. Rivard examined the sensitivities of Cohort Analysis and projections of catch biomass (Rivard, $1981)$ as well as those of VPA and equilibrium yield (Rivard, 1982). He also computed variances for shortterm projections (Rivard, 1981). Gavaris and Gavaris (1983) used Rivard's method to obtain variances for projected yicld.

In recent years, several authors tried to extend the VPA model so that effort data or abundance indices are taken into account (Fournier and Archibald, 1982; Pope and Sheperd, 1985; Gudmunsson, 1986). With these methods, commonly referred to as "calibration of VPA", VPA equations become a multiple regression problem. Hence, it is possible to estimate the variance of VPA results. These models generally need statistical assumptions, for instance the distribution of catch data, and additional assumptions about population dynamics, the relationship between fishing mortality and fishing effort or the "separability" hypothesis (Deriso and Quinn, 1985). Rivard (1983) studied the sensitivity of catch projections estimated when an independent measure of stock size was used to "tune" the Cohort Analysis. More recently, Gavaris (1988) applied non-linear estimation theory and calculated a variance-covariance matrix for VPA results.

Finally, Prager and MacCall (1988) eslimated variances of biomass estimates and sensitivities of MacCall's VPA approximation with was an improvement over Pope's approximation. They computed estimations of catch-at-age cstimale variances. The method was applied to a large series of data and they provided in fine confidence intervals for biomass estimates.

In this paper, VPA equations are formulated without any approximation and in the case of a series of cohorts. Calibration is not performed, but terminal mortality coefficients used as inputs to the VPA were cxiracted from the report of an ICES working group (Anon., 1989). They derive from a VPA "tuned" by the Laurec method (Laurec and Shepherd, 1983). Since diagnoses of fish stocks are needed for management decisions, it should be emphasized that mortality rates and stock sizes are only intermediate results. $\boldsymbol{A}$ global assessment of the stock is given by population biomass or yield per recruit (Thompson and Bell, 1934; Beverton and Holt, 1957). In this way, Prager and MacCall (1988) were interested in biomass estimation. Yield per recruit is chosen here because it is not only a diagnosis, but also allows long-term equilibrium predictions (Laurec and Le Guen, 1981). In the second section, an average fishing mortality vector is computed from VPA results. It represents the reference exploitation pattern. Other fishing mortality vectors are derived from this pattern. The basic equations are then used to calculate yield corresponding to each fishing mortality vector. The third section deals with the analysis of first-order sensitivities of VPA estimates as well as yield per recruit to all input parameters. The Delta-method, introduced by Cramer (1961), is also implemented at the first order to assess variances of VPA results and yield per recruit.

Finally, the model is applied to the Celtic Sca cod stock. Variance estimators of catch-at-age data are computed from the procedure used by IFREMER to sample commercial landings at Brittany's ports (Pelletier, 1990). 


\section{VIRTUAL POPULATION ANALYSIS}

VPA is an iterative procedure which estimates cohort sizes and fishing mortality rates at each age from the following equations:

$$
\begin{gathered}
\mathrm{N}_{i j}=\mathrm{N}_{i+1, j+1} \exp \left(\mathrm{F}_{i j}+\mathrm{M}_{i}\right) \\
\mathrm{C}_{i j}=\mathrm{N}_{i+1, j+1} \frac{\mathrm{F}_{i j}}{\mathrm{~F}_{i j}+\mathrm{M}_{i}}\left[\exp \left(\left(\mathrm{F}_{i j}+\mathrm{M}_{i}\right) \Delta \mathrm{T}_{i}\right)-1\right]
\end{gathered}
$$

where the notations for the $j$-th year and the $i$-th age/time interval are:

$\Delta \mathrm{T}_{i}$, time interval between age $i$ and age $i+1$.

$\mathrm{C}_{i j}$, catches in numbers.

$\mathrm{N}_{i j}$, cohort size in numbers.

$F_{i j}$, fishing mortality rate.

$\mathbf{M}_{i}$, natural mortality rate.

The time intervals is supposed to be equal to one year and it is assumed that natural mortality is not year-dependent. In the following, the subscript $j$ will be omitted in order to simplify the equations.

This system is non-linear but is solvable since it is based on recurrence equations. Given the terminal lishing mortality rate for each cohort (i.e. the fishing rate corresponding to the last available catch data of each cohort), a back-calculation successively provides estimates of cohort size and fishing mortality from catches and natural mortality. As described by Rivard (1982), the calculation of fishing mortality derives from a minimization (according to the Newton-Raphson method) of the equation:

$$
\mathrm{C}_{i}-\mathrm{N}_{i+1} \frac{F_{i}}{\mathrm{~F}_{i}+\mathrm{M}_{i}}\left(\exp \left[\left(\mathrm{F}_{t}+\mathrm{M}_{i}\right) \Delta \mathrm{T}_{i}\right]-1\right)
$$

Then, equation (1) is used to obtain cohort size. The recurrence continues to the youngest age group for which catch data are available. With respect to the last age group, identified by the subscript $T$, the corresponding cohort size may be estimated in two different ways:

- If $T$ only represents the fish at age $T$, cohort size is given by:

$$
\mathrm{N}_{\mathrm{T}}=\mathrm{C}_{\mathrm{T}} \frac{\mathrm{F}_{\mathrm{T}}+\mathrm{M}_{\mathrm{T}}}{\mathrm{F}_{\mathrm{T}}\left(1-\exp \left[-\left(\mathrm{F}_{\mathrm{T}}+\mathrm{M}_{\mathrm{T}}\right) \Delta \mathrm{T}_{\mathrm{T}}\right]\right)}
$$

- If $T$ stands for a "plus-group", i.e. fish of age T or older, cohort size becomes:

$$
\mathrm{N}_{\mathrm{T}}=\mathrm{C}_{\mathrm{T}} \frac{\mathrm{F}_{\mathrm{T}}+\mathrm{M}_{\mathrm{T}}}{\mathrm{F}_{\mathrm{T}}}
$$

There is no approximation for VPA and the general case of an age-dependent natural mortality coeflicient is considered as well as any value for the time interval between consecutive age groups.

\section{LONG-TERMI EQUILIBRIUNI YIELD PER RECRUIT}

For fisheries management purposes, VPA only provides intermediate results. Actually, the analysis of $F_{t}$ and $N_{i}$ gives a faint idea of global stock evaluation. However, an average exploitation pattern can be computcd from VPA mortality estimators and defines the reference exploitation paltern: $\bar{F}_{l}$ is the reference mortality rate for age $i$. Then equations (1) and (2) allow to calculate the long-term equilibrium yicld per recruit (Thompson and Bell, 1934) resulting from this exploitation pattern. In other words, the total yield in weight produced by a group of recruits entering the fishery is computable by integrating all the catches in weight over the fishable life span of these recruits, as written in equation (6). If the exploitation pattern and the annual recruitment remain unchanged for some years, the fishery will reach an equilibrium, i.e. the annual yield per recruit will be constant and equal to the average fish weight produced for one young recruit.

$$
\begin{aligned}
\mathrm{Y}_{r}=\sum_{i=1}^{\mathrm{T}-1} \frac{\bar{F}_{i} \mathrm{~W}_{t} \mathrm{~S}_{i}}{\mathrm{Z}_{i}}\left(1-\exp \left(-\mathrm{Z}_{i} \Delta \mathrm{T}_{i}\right)\right) \\
\quad+\frac{\overline{\mathrm{F}}_{\mathrm{T}} \mathrm{W}_{\mathrm{T}}}{\mathrm{Z}_{\mathrm{T}}}\left[1-(1-\mathrm{IGP}) \exp \left(-\mathrm{Z}_{\mathrm{T}} \Delta \mathrm{T}_{\mathrm{T}}\right)\right]
\end{aligned}
$$

where IGP is 1 if there is a "plus-group", otherwise 0 ; and for the $i$-th age/time interval,

- $\mathrm{W}_{l}$ is the age-specific mean weight in the stock. Fish growth during the year is therefore neglected. Effects of change in average weight due to age selectivity of fishing mortality are also ignored.

- $Z_{i}$ is the total mortality rate expressed by:

$$
\mathrm{Z}_{\mathrm{l}}=\mathrm{F}_{i}+\mathrm{M}_{\mathrm{i}}
$$

$-S_{i}$ is the proportion of survivors with respect to recruitment. Its value is given by the equation:

$$
S_{i}=\exp \left(-\sum_{j=1}^{i-1}\left(F_{j}+M_{j}\right) \Delta T_{j}\right)
$$

If equilibrium yields per recruit are computed for a range of exploitation patterns, it is possible to compare stock situations induced by these paterns. Hence, equilibrium yield per recruit is a working tool for fisheries management as it shows how a given stock responds to long-term changes, for example fishing gears, mesh size or intensity of fishing.

In order to asses the consequences of such changes, other patterns are also simulated. They are defined by new values for age-specific fishing mortalities, noted $\mathrm{F}_{i}^{\prime}$ hereafter, in equation (9). Per Paulik and Bayliff (1967), these mortality coefficients are written in a 
product form to simplify the output interpretation:

$$
\forall_{i}, \quad F_{i}^{\prime}=\mu_{i} F_{i}
$$

where $F_{i}$ is the reference mortality rate for age $i$, i.e. the average coefficient defined above and $\mu_{i}$ an effort multiplier. This formulation allows simulation of an age-dependent effort modification such as a mesh size change. The multiplier will then be age-dependent. The reference exploitation pattern obviously corresponds to a constant multiplier equal to 1 .

From (6), the long-term stock situation induced by this new exploitation pattern is quantified through the corresponding yicld per recruit by the expression:

$$
\begin{aligned}
Y_{r}(\mu) & =\sum_{i=1}^{T-1} \frac{\mu_{i} \bar{F}_{i} W_{i} S_{i}}{Z_{i}}\left(1-\exp \left(-Z_{i} \Delta T_{i}\right)\right) \\
& +\frac{\mu_{\mathrm{T}} \bar{F}_{\mathrm{T}} W_{\mathrm{T}}}{Z_{\mathrm{T}}}\left[1-(1-\mathrm{IGP}) \exp \left(-\mathrm{Z}_{\mathrm{T}} \Delta \mathrm{T}_{\mathrm{T}}\right)\right]
\end{aligned}
$$

If a yield per recruit is calculated for each different age-independent effort multiplier, the yield can be plotted against the multiplier. Hence, in the following, the effort multiplier will not depend upon age and will simply be noted $\mu$. Moreover, one wants to assess the gain or loss on the yield per recruit arising from a change in effort. A "gain-loss" function is then defined by:

$$
\Phi(\mu)=100\left(Y_{r \mu} / Y_{r 1}-1\right)
$$

This function represents the percent variation in yield induced by a shift of the effort multiplier from the reference exploitation pattern to the pattern defined by $\mu$.

\section{SENSITIVITY COEFFICIENTS AND VARIANCE ESTINIATORS}

Since all data used for VPA and the yield model are subject to various types of errors, it is important to know the behaviour of the models with respect to these uncertainties, in other words, robustness of VPA and the yield model. One method is to express crrors on the results as a function of input parameter errors. Hence, first-order sensitivity coefficients may for instance be defined.

In that way, mortality coefficient and cohort size for age $i$ are considered as the following functions:

$$
\begin{aligned}
& F_{i}=F\left(C_{i}, C_{i+1}, \ldots, C_{T}, M_{i}, M_{i+1}, \ldots, M_{T}, F_{T}\right) \\
& N_{i}=N\left(C_{i}, C_{i+1}, \ldots, C_{T}, M_{i}, M_{i+1}, \ldots, M_{T}, F_{T}\right)
\end{aligned}
$$

where $F_{T}$ is the terminal mortality rate for the relevant cohort.

The first-order sensitivity coefficient of $F_{i}$ with respect to $\mathrm{C}_{j}$, catches of age $j$ for the considered cohort, is defined as:

$$
\mathrm{B}\left(\mathrm{F}_{i} / \mathrm{C}_{j}\right)=\frac{\hat{c} \mathrm{~F}_{i}}{\mathrm{~F}_{i}} / \frac{\hat{c} \mathrm{C}_{j}}{\mathrm{C}_{j}} \approx \frac{\Delta \mathrm{F}_{i}}{\mathrm{~F}_{i}} / \frac{\Delta \mathrm{C}_{j}}{\mathrm{C}_{j}}
$$

This coefficient is sometimes called elasticity of $F_{i}$ with respect to $C_{j}$ and can be interpreted as the percent variation of $F_{j}$ implied by a unit variation of $\mathrm{C}_{j}$. This correspondence is approximately true for small perturbations of the input parameters as it is based on a first-order expansion. The validity of this interpretation also depends on the degree of nonlinearity of the relationship between $F_{i}$ and $C_{j}$. Analogous coefficients are computable for reference mortality vector, yicld per recruit and for function $\Phi$. Indeed, since the estimation of these three quantities requires VPA mortality rate estimates and average weights at age, they can be considered, in this case, as functions of mean weights and VPA input parameters.

and

$$
\begin{gathered}
\bar{F}_{i}=F\left(C, M, \tilde{F}_{T}\right) \\
Y,(\mu)=Y\left(C, M, \tilde{F}_{T}\right)
\end{gathered}
$$

$$
\Phi(\mu)=\Phi\left(C, M, \tilde{F}_{T}\right)
$$

where $C, M$ and $\tilde{F}_{T}$ respectively correspond to the catch matrix, the natural mortality vector and the terminal mortality rate vector.

With respect to catches and natural mortality, "global sensitivities" are computed to obtain interpretable quantities instead of cocfficient matrices. Rivard (1982) calculated "overall sensitivity" of recruitment to parameters as:

$$
\mathrm{I}_{j}^{2}=\sum_{\theta}\left(\mathrm{B}\left(\mathrm{R}_{j} / 0\right)\right)^{2}
$$

where the subscript $j$ identifies the year and 0 represents an input parameter used to estimate recruitment $R_{j}$. Since many sensitivities are less than 1 in absolute value, squaring may somewhat distort the resulting coefficient. In this paper, global sensitivities are calculated by means of the following formulas:

$$
\begin{aligned}
& B_{\text {global }}\left(F_{i} / M\right)=\sum_{j}\left|B\left(F_{i} / M_{j}\right)\right| \\
& B_{\text {global }}\left(F_{i} / C\right)=\sum_{j k}\left|B\left(F_{i} / C_{j k}\right)\right|
\end{aligned}
$$

Similar expressions are used for stock size and yicld per recruit. For example, simultaneous unit variations are considered on each catch datum. If the consequences of all these variations through the VPA model are added, the resulting sensitivity of the fishing mortality rate will then be approximately equal to the sccond global coefficient defined in equation (18).

These coefficients correspond to additive simultaneous uncertainties. Hence, they probably overestimate 
the actual sensitivity of VPA results and equilibrium predictions to natural mortality and catches since errors of opposite signs may actually balance one another.

Sensitivity coefficients only provide a relative value of errors on the results. However, estimations of some input parameter errors, i.e. their variances, are sometimes available. This may be true for catches. There are then methods to estimate variances of the results.

The Delta-method was first introduced by Cramer (1961). An application to fishery science was shown in Laurec (1986). Calculation of the variance estimator is described in the Appendix for yieJd per recruit. In practice, since all input parameters are estimated separately here, all the covariance terms will be zero except those between catch estimates for the same year. Analogous formulas are derived for fishing mortality rates, cohort sizes, reference mortality vector and function $\Phi$. First-order estimates of variances and sensitivity coefficients are then achieved.

In computing these estimators, partial derivatives must be known. Fortunately, the recurrent nature of the procedure implies recurrence relations for the derivatives and moreover, the considered models rely on easily derivable equations so that the necessary derivatives can be calculated analytically. However, the time scries catch-at-age case is more complicated than the single cohort case because there are different types of cohorts in the scries: 1) some cohorts are complete, 2) the first ycars are missing for others and $3)$ some are not yet entircly exploited.

Once these expressions are obtained, variances of the input parameters must be known, $i$.e., age-specific catches and weights, natural mortality rates and terminal mortality rates. Catches are estimated by sampling commercial landings in ports, hence if the sampling process is known, the variance-covariance matrix may be estimated. Concerning weights, estimations generally results from adjustments with agelength keys and/or growth curves and a length-weight relation which is, for instance, an isometric function. If the standard deviation of these adjustments were available, the uncertainty of age-specific weights could be taken into account and variances could be computed. With regard to natural mortality, it exists no estimate for its variance. The mean value of the coeflicient is even supposed to be constant over all ages although this assumption is obviously wrong (Vetter, 1988) and its value is conjectured in most models. If the terminal mortality rate is estimated from calibration, the associated variance-covariance matrix may also be estimated (Gavaris, 1988). Prager and MacCall (1988) used cohort linkage to estimate terminal mortalities and they assumed an arbitrary non-zero variance for a "Iransfer coefficient". In this paper, "tuned" terminal mortality coeflicients are used but their variance-covariance matrix is unfortunately not availablc.
Hence, some input parameters may be considered as true stochastic variables resulting from a predefined sampling model or a statistical adjustment, i.e. their variance is expressible or at least computable, whereas others like natural mortality, are only "uncertain values".

Finally, I will first study the sensitivity of VPA along with yield per recruit to the different input parameters and then variances duc to quantifiable variances of some parameters, particularly catches. As natural mortality is conjectural, different values of this rate will be considered in the next section.

\section{APPICATION TO TIE CELTIC SEA COD}

The example of the Celtic Sea is herein analyscd, mainly due to the prevalence of French catches in the landings (Anon., 1989). The study focused on cod for which French landings represented $86 \%$ of total landings in 1987. Most of the trawlers come from southern Britlany's harbours (for instance Lorient and Concarneau), for which the sampling procedure for commercial catches is precisely defined. The corresponding data are available (Anon, 1989).

\section{Input parameters}

Fishing for cod in the Celtic Sca shows no seasonal pattern: landings are distributed rather evenly through the year. Catches in numbers are available from 1971 to 1987. Agc-specific mean weights are derived by combining British an French data weighted by numbers. For the years 1971-1980, weights were the same as in preceding years, but for latter years, they correspond to values known for the first quarters. Hence, it seems impossible to cvaluate the variance-covariance matrix for weights at age. Terminal mortality rate was estimated by "tuning" according to the LaurecSheperd method (Lauree and Sheperd, 1983). Natural mortality is supposed to be constant over all ages and equal to 0.2 but the whole algorithm takes into account an age-dependent coefficient (recurrence expressions of derivatives are not the same whether $M$ is constant or not). Moreover, trials were run for $\mathbf{M}=0.1$ and $\mathbf{M}=\mathbf{0 . 3}$.

\section{Variance-covariance matrix of catches}

The age-specific catches were estimated when landed in the harbours, both by sampling and by automatic registering. In Pelletier (1990), the complete sampling process and the associate statistical model were described so that catch variances and covariances were computed. This work was applied to French Cellic Sca cod landings in 1988. The variance-covariance matrix is shown in table I. Values correspond to the coefficients of variation and covariation and covariation. Since it was not possible to have the 
Table 1. - Percent coefficients of variation and covariation for estimations of Celtic Sea cod landings in 1988.

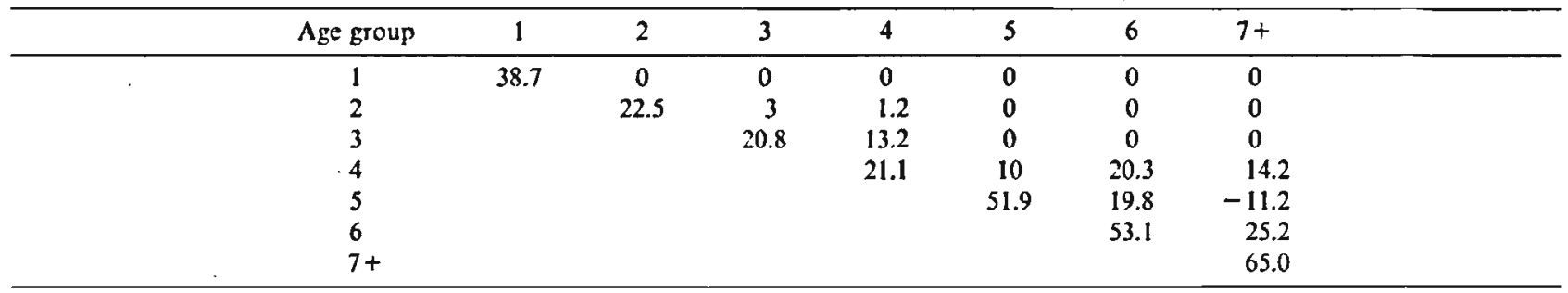

sampling planning for preceding years, these coefficients were assumed to be the same for the previous years considered in the VPA, i.e. from 1971 to 1987. Covariances between two different years vanish because of sampling procedure independence though, in this application, values come from the same computation. The sampling scheme took into account a stratification and three stages. Hence, variance comprises three components, but only one accounts for simple random sampling and therefore leads to a multinomial probability distribution in which all covariance terms are nagative. Given the actual sampling effort, many covariances finally appear to be positive on the whole.

\section{VPA results}

\section{Sensitizities}

VPA estimates consist of two-dimension matrices for cohort size and for mortality rate. $\Lambda$ sensitivity coclicient is computed for each element of these matrices and for each input parameter. With respect to the terminal mortality rate, only values for the first year, 1971, and the last year, 1986, are shown in table 2 in order to sum up the results. On the same ground, table 3 only mentions global coefficients for the year 1986 concerning catch data and natural mortality. As it was first stressed by Pope (1977) for Cohort Analysis, the sensitivity to the terminal mortality coefficient decreases as the back-calculation gets longer. However, recent years are rather sensitive. But, these are generally averaged to compute the reference exploitation pattern, which is required for calculating yicld per recruit. Unlike terminal mortality rate, sensitivities to catches and natural mortality are increasing functions of the number of backcalculations required to get the corresponding values. With regard to natural mortality, coefficients related to F vary from $16 \%$ (year 1986 , age 4 ) to $56 \%$ (years 1973 and 1974, age 1, not reported here) but most of them comprise between 25 and $30 \%$. Stock sizes are a little more sensitive: values vary from $14 \%$ (year 1987 , age 2) to $66 \%$ (year 1974, age 1 , not reported here). It should be noted that, unlike fishing mortalities, stock sizes for last year and last age group are calculated from the corresponding terminal mortality rate so that for a given age-year there is one more stage for computing size. This would then explain the skight increase in sensitivity for stock size with respect to fishing mortalities.

The global sensitivities to catches are greater than those for natural mortality: they comprise between $89 \%$ (year 1986, age 4) and 200\% (years 1972, 1974 and 1976 , age 1 , not reported here) for fishing mortalities $F_{l}$ and between $56 \%$ (year 1986, age 1) and $100 \%$ (years previous to 1981 , all ages, not reported here) for the sizes. Many coefficients are equal to $100 \%$ for stock sizes $\mathrm{N}_{l}$. This peculiarity due to the formulation of the model was already noted by Rivard (1982). $F_{i}$ is more sensitive to catches than $\mathrm{N}_{i}$, but for both, the younger ages are more sensitive to catches. Finally, sensitivities to $M_{i}$ are higher as $M_{i}$ increases.

Table 2. - Percent sensitivities of VPA results with respect to terminal mortality rate for $\mathbf{M}=0.2$.

\begin{tabular}{ccccccccc}
\hline Age group & 1 & 2 & 3 & 4 & 5 & 6 & 7 \\
\hline$F_{\mathrm{T}}$ component for $\mathrm{F}_{i}(1971)$ & 1.6 & 1.9 & 2.9 & 7.4 & 13.2 & 20.1 & 100 \\
$\mathrm{~F}_{\mathrm{T}}$ component for $\mathrm{F}_{i}(1986)$ & 66 & 47 & 53 & 44 & 52 & 16 & 100 & -26 \\
$\mathrm{~F}_{\mathrm{T}}$ component for $\mathrm{N}_{i}(1971)$ & -1.4 & -1.3 & -2 & -5.4 & -11 & -15 & -26 \\
$\mathrm{~F}_{\mathrm{T}}$ component for $\mathrm{N}_{\mathrm{i}}(1986)$ & -59 & -32 & -38 & -26 & -37 & -11 & -20 & \\
\hline
\end{tabular}

Table 3. - Percent sensitivities for VPA results with respect to natural mortality and catches for $\mathbf{M}=0.2$.

\begin{tabular}{|c|c|c|c|c|c|c|c|}
\hline Age group, & 1 & 2 & 3 & 4 & 5 & 6 & 7 \\
\hline$M$ component for $F_{l}(1986)$ & 23 & 18 & 19 & 16 & 19 & 24 & 0 \\
\hline$M$ component for $N_{l}(1986)$ & 30 & 20 & 22 & 17 & 22 & 24 & 20 \\
\hline C component for $F_{t}(1986)$ & 131 & 105 & 105 & 89 & 107 & 136 & 0 \\
\hline
\end{tabular}


Table 4. - Percent coefficients of variation (CV) for fishing mortalities, cohort sizes and reference exploitation pattern.

\begin{tabular}{lccccccc}
$\quad$ Agc group & 1 & 2 & 3 & 4 & 5 & 6 & $7+$ \\
\hline CV of $F_{r}-1986$ & 36 & 17 & 17 & 20 & 42 & 57 & 0 \\
CV of $N_{r} 1986$ & 11 & 13 & 11 & 16 & 28 & 41 & 65 \\
CV of Fref $_{-1986}$ & 14 & 7 & 7 & 10 & 14 & 19 & 0 \\
\hline
\end{tabular}

\section{Variances}

$\Lambda$ variance-covariance matrix for catches only was first examined. Coefficients of variation (CV's) were compouted for VPA results and for the reference fishing mortality. They are reported in table 4 for $\mathrm{M}=0.2$ and the year 1986 .

With respect to fishing mortalities, CV's are found to be roughly proportional to catch CV's, except for the terminal age group. Hence, values do not depend much on the year. Conccrning stock sizes, CV's are smaller and increase as the age group is older. On the whole, they comprise between $11 \%$ and $65 \%$.

In a second run, a relative uncertainty of $50 \%$ was considered for each natural mortality rate, i.e. a diagonal variance-covariance matrix for M. This value is totally arbitrary, but respective variance components for natural mortality and catches can then be compared. In this case, CV's increased up to $75 \%$ (for 1974) but values for 1986 only vary from 25 to $64 \%$. If natural mortality is higher $(M=0.3)$, CV's are also higher, in relation to the increased sensitivity to M. Lastly, CV's for the reference mortality vector are smaller since it is computed from an average.

\section{P'redictions}

\section{Sensitizities}

Opposite VPA results, yicld per recruit always depends on several cohorts since it is computed from a mean mortality vector. This average was calculated for the years 1981 to 1987 , because the data were more reliable from $198 \mathrm{I}$ on. For each yicld per recruit, a global sensitivity was computed with respect to the corresponding $F_{T}$. Concerning catches and natural mortality rates, global coefficients were evaluated as for VPA results. With respect to weight, it can easily be noticed from the equations that the global sensitivity of yicld per recruit is equal to one, which is not negligible. Results are shown in figures 1 and 2 for yield per recruit and in figures 3 and 4 for function $\$ 1$. These coefficients should not be directly compared with those from VPA because global sensitivities represent more terms for predictions. Function $\Phi$ appears to be muc more sensitive than yield per recruit and shows a peak of sensitivity for low effort

\footnotetext{
'Sensitivities to $F_{T}$ and $W_{1}$ were not considered for the "gainloss" function.
}

multipliers. This maximum is found when the increasing function $\$$ changes signs.

Considering the effect of natural mortality, sensitivitics of both predictions increase as $M_{i}$ ( $f i g .1$ to 4 ). This augmentation is focused on low multipliers (0.1 to 1). Total sensitivity seems to be a decreasing function of fishing effort. The $F_{T}$ component is the main one for yield per recruit but parts due to the different input parameters depend both on eflort and input parameters ( $\mathbf{M}$ was the only one variable here). If the influcnce of each weight is considered (these results are not reported here), the maximum coefficient moves towards the young age groups as the effort grows: ages 3 and 4 for $\mu<1$, age 2 for $\mu>1$. Actually, this means that sensitivities to $\mathrm{W}$ concentrate on age groups which form the main part of the biomass. Figures 5 and 6 show the sensitivity breakdown by input parameters for plausible multiplier values (i.e. around 1). Corresponding total sensitivities are 4.1 for $M=0.2$ and 4.3 for $M=0.3$.

\section{Variances}

$\Lambda$ s pointed out before, trials were firstly realised for three different natural mortalities and in the case of a variance-covariance matrix for catches only. Results are presented in figures 7 to 10 . Concerning mean values of yield per recruit and function $\Phi$, the stock is typically overexploited. If the effort were reduced by $10 \%$ for instance, the relative gain would be $5 \%$ for $M=0.2$ (see fig. 10 ) and $3 \%$ for $M=0.3$. For a given value of the effort multiplier, the gain or loss is always higher when $\mathbf{M}=0.2$. Similarly, maximum yield is greatly diminished when $M$ increases. Hence, the mean value of $M$ is rather influential. Considering variances, even if catch variances are globally rather important (sec table 1), the induced variance component is very low, CV's being less than $8 \%$ for yield per recruit. Variance is greater for increasing efforts. IVith regard to function $\Phi, \mathrm{CV}$ 's are somewhat higher, generally comprising between 8 and $13 \%$ except for very low efforts.

Secondly, propagation of natural mortality and weight variability was studied. Figures 11 and 12 respectively show CV's of threc yiclds $(\mu=0.9, \mu=1$, $\mu=1.1)$ and two functions $\Phi(\mu=0.9, \mu=1.1)$ versus $C V$ of $M_{t}$ and $W_{t}$. For this range of multipliers, effort value has no effect on numerical behaviour of yicld or function $\Phi$. Yicld per recruit appears to be more stable than function $\Phi$.

The variance component induced by terminal mortality rate estimates was not dealt with here. 
D. Pelletier
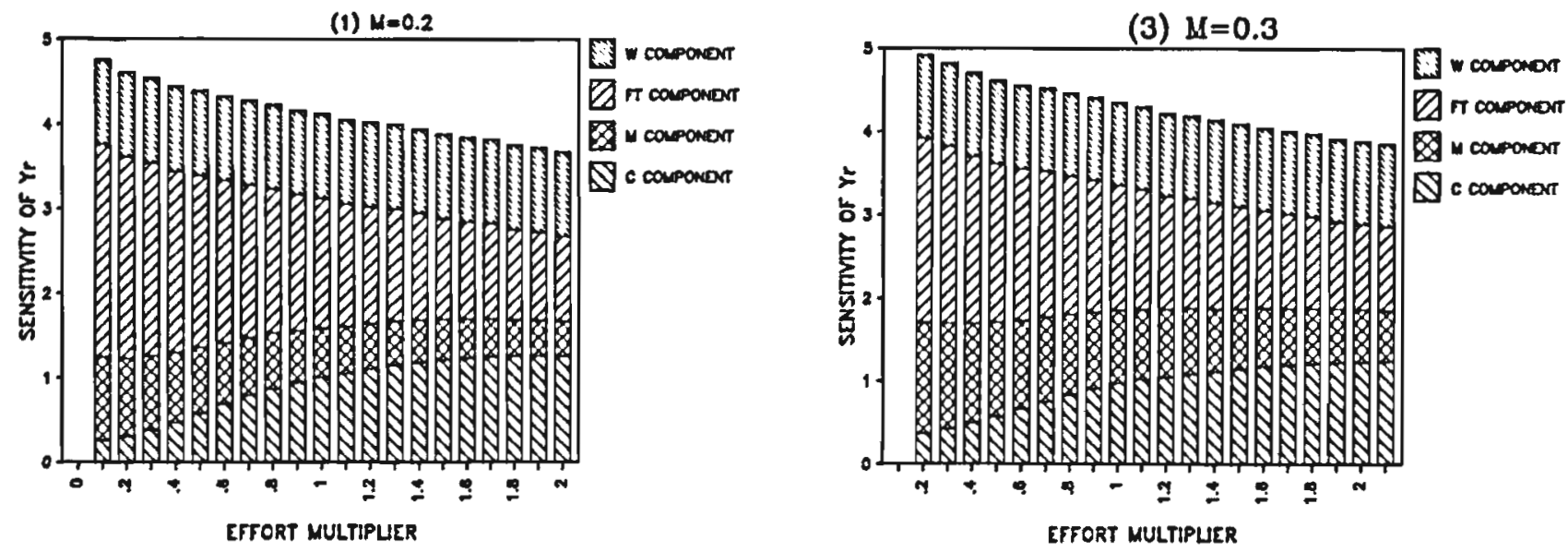

Figure 1 and 3. - Sensitivity of gield per recruit to catches (C). natural mortality (M) and terminal mortality rate ( $\left.F_{T}\right)$ versus effort muluplier. Components are stacked. (1) $M=0.2 ;(3) M=0.3$.
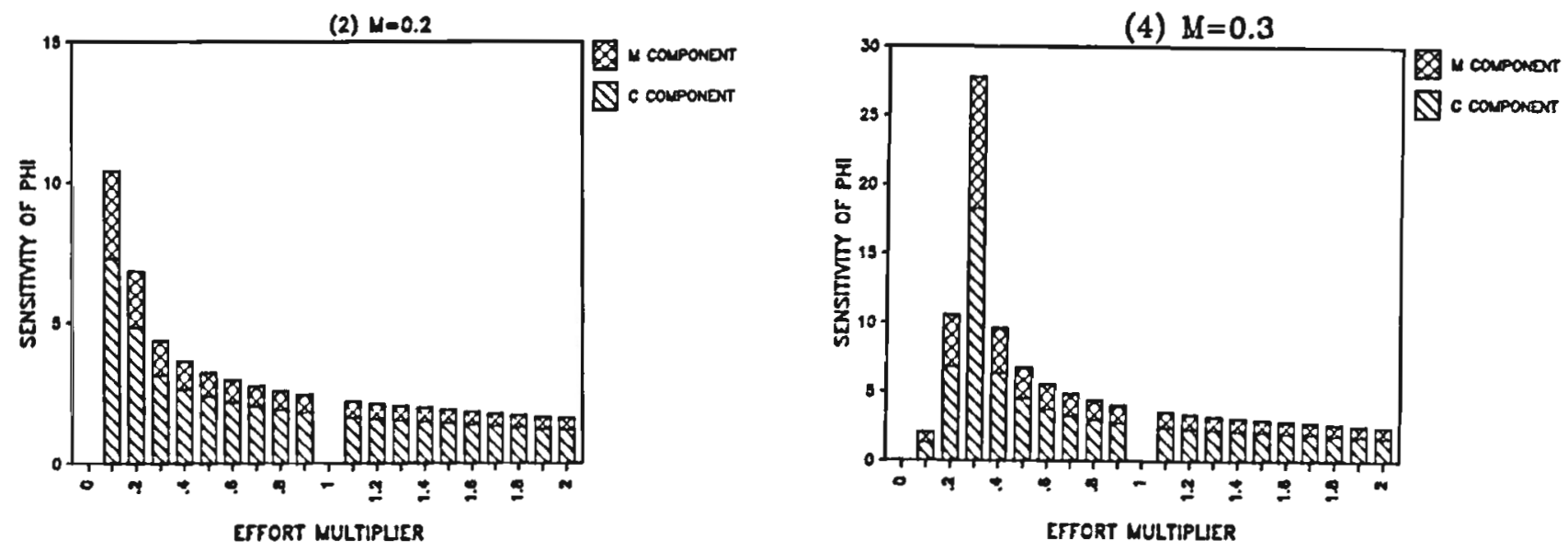

Figure 2 and 4. - Sensitivity of function $\Phi$ to catches $(C)$ and natural mortality (M) versus the cffort multiplier. $M$ component is stacked on Cone. (2) $\mathrm{M}=0.2 ;(4) \mathrm{M}=0.3$.

\section{DISCUSSION}

\section{Comparison of VPA and the yield per recruit model}

Sensitivities to all input parameters and variance estimators were computed for both series of results. Numerical behaviours of the two models differ significantly from a qualitative and quantitative point of view. An approximate comparison of sensitivitics is shown in table 5. Concerning VPA, estimates for recent years appcar to be sensitive to terminal mortality rate because convergence does not hold for these years. However, reference exploitation pattern is generally computed from recent years since it is required to assess long-term consequences of the present fishery situation. Contrary to VPA outputs, yield per recruit seems to be less sensitive. Sensitivity to catches probably vanishes because these data are not used during prediction calculation. For most estimators, the maximum sensitivity component corresponds to terminal mortality rate.

In other respects, as was noted by Sampson (1988) and Prager and MacCall (1988), the mean value of input parameters influences not only the mean result, but also the sensitivities. For instance, when natural mortality $\mathbf{M}$ increases, yield per recruit and the "gainloss" function show different mean curves and higher sensitivities. Moreover, results are all the less sensitive to $\mathrm{M}$ because exploitation increases.

Secondly, considering variances of yicld per recruit, the estimations show rather small cocfficients of variation when only catch variances are taken into account, even if these variances are rather high. Results are qualitatively similar for the "gain-loss" function. Concerning natural mortality and weights, corresponding variance components have the same magnitude as the catch component (in this cxample) 


\section{Sensitivity of $\mathrm{Yr}$}

(s) $M=0.2$

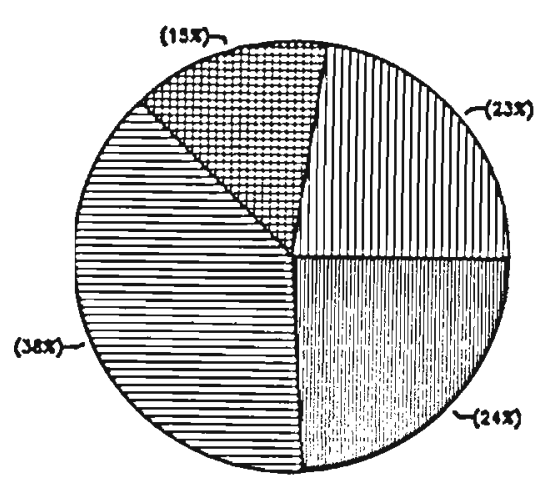

Sensitivity of $\mathrm{X}_{\mathrm{r}}$ (6) $M=0.3$

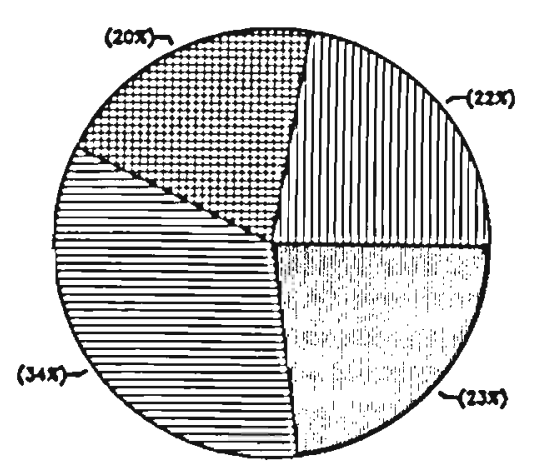

Figure 5 and 6. - Average sensitivity components of yield per recruit for effort multipliers between 0.9 and 1.1 . (5) $M=0.2$; (6) $M=0.3$. C represents catches, $M$ natural mortality, $F_{T}$ terminal mortality and W weights.

but are smaller for yield per recruit compared to to function $\Phi$.

Sensitivity analysis stresses parameters which are crucial for the stability of the results. Accurate estimators, or at least variances, should be obtained for these parameters. With respect to yield per recruit, tcrminal mortality rate is important.

\section{Variance estimates for input parametcrs}

With regard to weights, it is necessary to estimate the variance-covariance matrix. This is possible if weights are provided by sampling commercial catches. Concerning catches, a variance-covariance matrix was computed from an analytical expression based on the complete sampling scheme (Pelleticr, 1990). It appears that, although an estimate of the catch variance-covariance matrix is required, accuracy of catch estimators is not crucial for old age groups because they are not important for yield per recruit or for a global diagnosis as the biomass. $\Lambda$ ge groups 1,2 and 3 are only worth of an accurate cstimation. This also holds for weight estimators. Knowing the importance of accuracy of catch and weight estimates and propagation of their variance through the models used allows to adapt the sampling effort. Planning of the sampling program may therefore be improved.

For natural mortality, $20 \%$ of the sensitivity is neglected at most when $M$ is assumed to be constant. Even if the variance component is not estimable, this should be taken into account for decisions which may be inferred from models results. Moreover, two bias terms are ignored: the first arises from a biased estimation of $M$ and results in a first-order term in output variance (and bias, not estimable here), whereas the second, due to the first-order approximation, is a second-order term in output variance.

With respect to terminal mortality, the variance component was unfortunately not computable in this example. According to sensitivity analysis (fig. 5 and 6), approximately $35 \%$ of the total sensitivity of yicld per recruit is due to this parameter. Terminal mortality rate is provided here by a "separable" VPA, which is an analysis of variance. Hence, an estimation of the variance should be obtainable for further applications. Sensitivities and variances are complementary in that the first provide an idea of absolute robustness of the models used whereas the second fits robustness with the ranges of variations of the concerned parameters. This scaling requires variances of all input parameters.

\section{Methodology}

The non-linear nature of the model implies that first-order calculations are drastic approximations. Yicld per recruit is estimated from fishing mortality estimates, which are themselves estimated from VPA. Actual input parameters for yield per recruit are therefore the same as for VI'A, plus age-specilic weights. Hence, sensitivities and variances must be cstimated with respect to these parameters. If partial derivalives are computed with regard to intermediate

Table 5. - Comparison of sensitivities with respect to all input parameters for VPA and the yicld per recruit model. Crosses approximately stand for the magnitude of sensitivities as computed in the example. $\mathrm{F}_{\mathrm{T}}$ is the terminal mortality. $\mathrm{M}$ is the natural mortality.

$\begin{array}{lccccc}\quad \text { Input parameter } & F_{r} & \text { Weights } & \text { Catches } & \text { M } & \text { Convergence } \\ \text { VPA for older years } & ++ & --- & +++++ & +++ & \text { Yes } \\ \text { VPA for recent years } & +++ & --- & ++++ & ++ & \text { No } \\ \text { Yicld per recruit } & ++ & + & + & + & \text { No }\end{array}$


(7) $M=0.1$

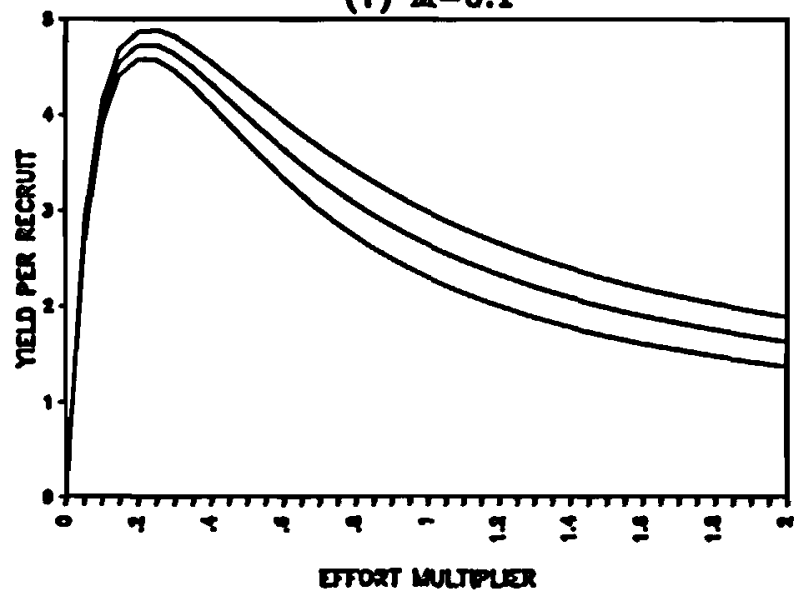

(8) $\mathrm{M}=0.2$

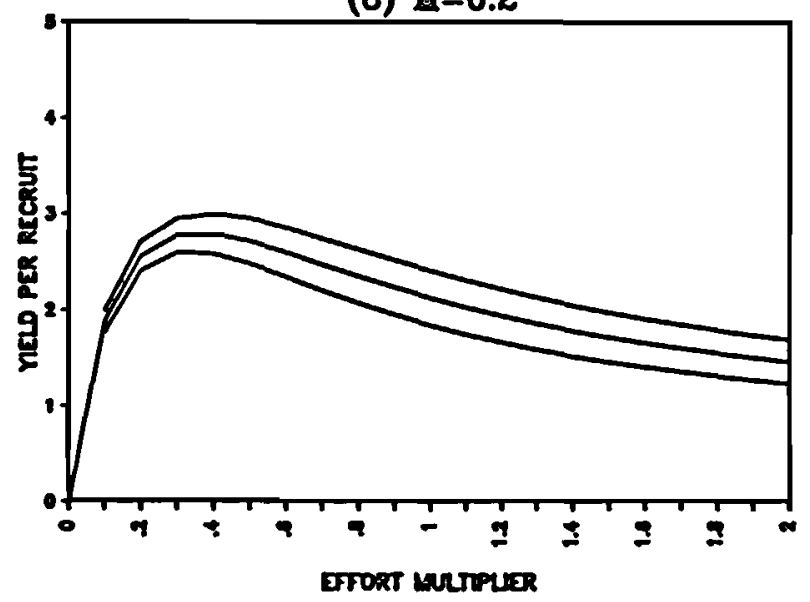

Figure 7 to 9. - Yield per recruit versus effort multiplier. The surrounding curves represent yicld plus or minus two standard deviations. (7) $M=0.1,(8) M=0.2$, (9) $M=0.3$.

estimators, the first-order approximation is used twice. This diminishes accuracy of the results and augments biases.

In other respects, analytical, i.e. exact derivatives are computed in this paper. Algorithms are constructed for an age-dependent natural mortality, which corresponds to reality, even if the value choosen in the application is constant. Indeed, estimators are different when $M$ is assumed to be constant. At last, confidence intervals were not constructed since there is no evidence for normality of estimators. Even if input parameters were supposed to be gaussian, the non-linear nature and the absence of a least square criterion would prevent any normality of the results. Therefore, confidence intervals and statistical tests should be avoided.
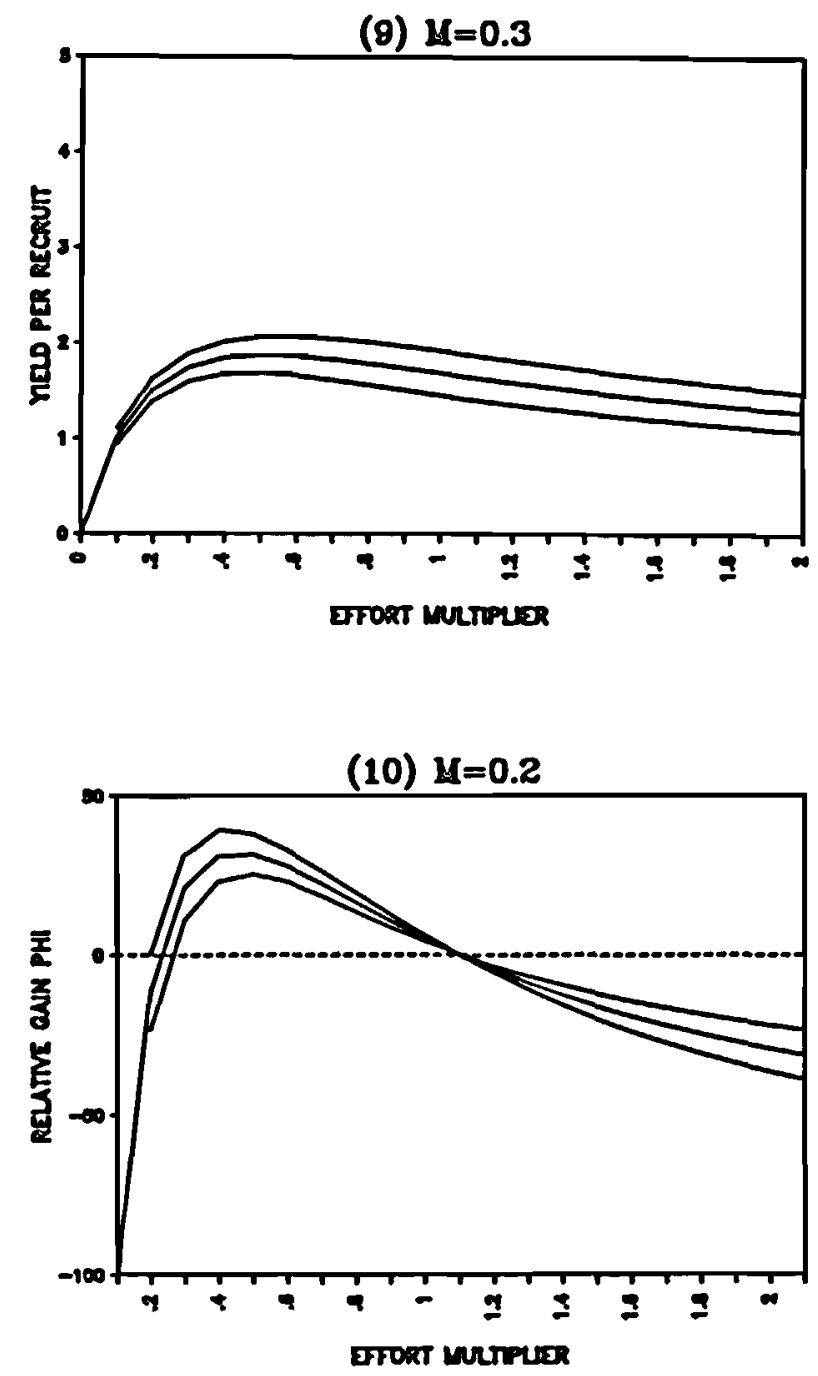

Figure 10. - Function $\Phi$ versus effort multiplicr. Surrounding curves represent the function plus or minus two standard deviations. $\mathrm{M}=0.2$.

The example of the Celtic Sea cod was herein analysed, however a comparison with Prager and MacCall's work (1988) would be interesting. They used a linkage algorithm to reduce the source of variability due to terminal mortality rate $F_{T}$, but since sensitivities were not produced, it can not be judged whether the poor $F_{T}$ variance component is a consequence of the sensitivity or the variance of $F_{T}$ itself. The problem is similar for the $\mathbf{M}$ component, which is prevalent in the total biomass variance. Also, they were interested in biomass estimates, which is a global evaluation of slock, but not a prediction. In this analysis, basic equations are used again to obtain yicld per recruit, hence the model's behaviour is probably different.

In conclusion, these results assess respective influences of the different input parameters on both VPA 
(11) ERROR ON M

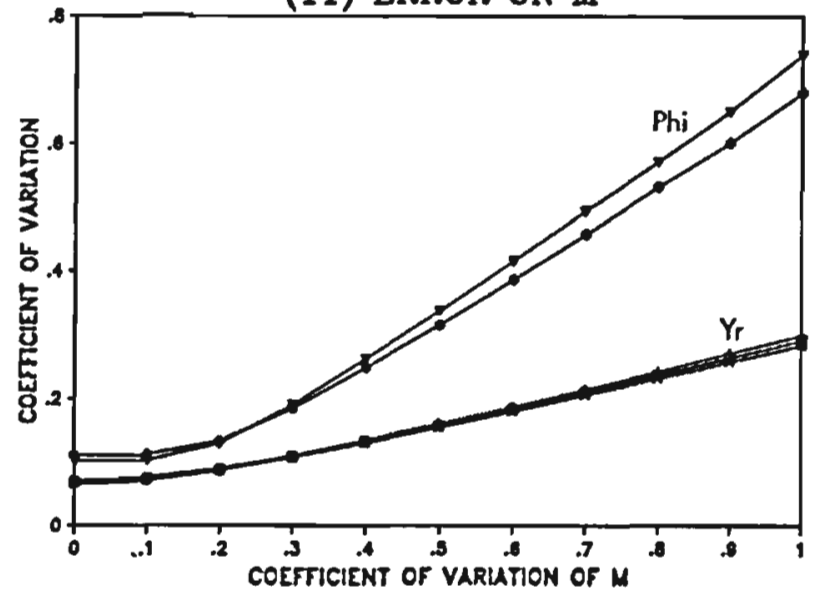

(12) ERROR ON W

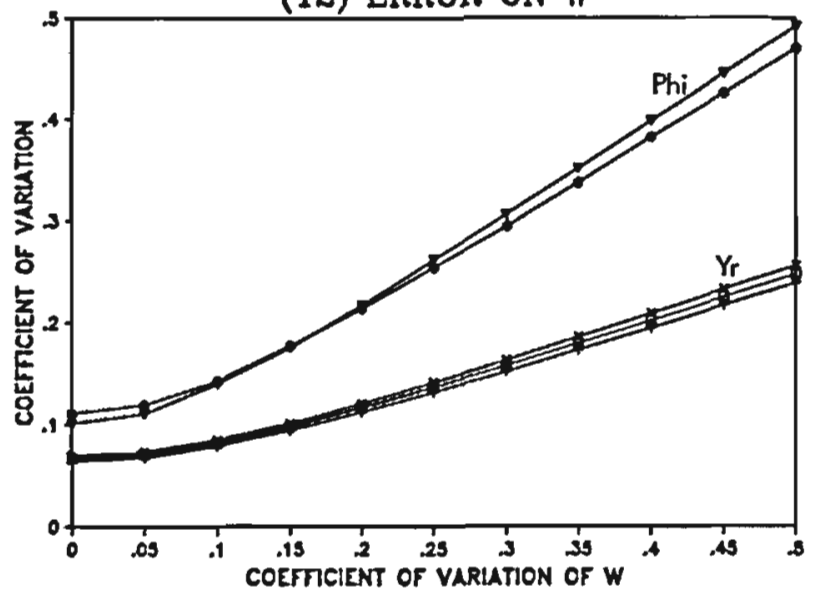

Figure 11 and 12. - Coefficients of variation of function $\Phi$ and yicld per recruit versus the cocfficient of variation of natural mortality (I1) and weights at agc (12). In both cascs, the two upper curves correspond to function $\Phi(\mu=0.9$ and $\mu=1.1)$ and the three lower curves correspond to yicld per recruit $(\mu=0.9, u=1$ and $\mu=1.1)$.

and predictions. They prove that variances should be estimated for terminal mortality rates and, to a lesser extent, for age-specific weights. On the whole, this analysis stresses the fact that ultimate results, $i . e$. yield per recruit in this example, generally behave in a different way from intermediate results.

First-order estimations may not be sufficient. These results may be validated by second-order developments and by simulations. Obtaining analytical expressions for second derivatives is quite tedious, but this should be dealt with in future works. Simulation probably provides more accurate results but is more CPU-time consuming. Hence, if outputs were validated at the second or even at the first order, this would demonstrate that the Delta-method is not only an easy analytical tool, but also produces reliable results which are useful for fisheries management decisions.

\section{Acknow ledgements}

I sincerely thank two anonymous reviewers who improved the paper with their helpful comments.

\section{REFERENCES}

Anon., 1989. Report of the Irish Sca and Bristol Channel working group, parts I and II. ICES CM, $222 \mathrm{p}$.

Beverton R. J., S. J. Holt, 1957. On the dynamics of cxploitcd fish populations. UK Min. Agri. Fish Food, Fishery Investigations, 2, 19, $533 \mathrm{p}$.

Cramer H., 1961. Mathematical methods of statistics. Princeton Univ. Press., 9th cd., 575 p.

Deriso, R. B., T. J. Quinn II, and P. R. Ncal., 1985. Catchage analysis with auxiliary information. Can. J. Fish. Aquat. Sci., 42, 815-824.

Fournier D., C. P. Archibald, 1982. A general theory for analysing catch at age data. Can. J. Fish. Aquat. Sci., 39, 1195-1207.

Gavaris S., 1988, An adaptive framework for the estimation of population size. CAFSAC Res. Doc. 88/29, $12 \mathrm{p}$.

Gavaris S., C. A. Gavaris, 1983. Estimation of catch at age and its variance for groundlish stocks in the Newfoundland region. In: Doubleday IV. C.. D. Rivard, 1983.
Sampling commercial catches of marine fish and invertebrates. Can Spec. Publ. Fish. Aquat. Sci., 66, 290 p.

Gulland J. A., 1965. Estimation of mortality rates, Annex to Arctic fisheries working group report, ICES C.M 1965 , Doc. No. 3, 9 p (mimco).

Gudmundsson G., 1987. Time scries models of fishing mortality rate. ICES Doc. CMI 1987/D, 6.

Laurec A., J. C. Le Guen, 1981. Dynamique des populations marines exploitces. Rapp. Scient. Tech. No. CNEXO, $118 \mathrm{p}$.

Laurec A., J. G. Sheperd, 1983. On the analysis of catch and effort data. J. Cons. int. Explor. Mer, 41, 81.84.

Laurec A., 1986. Les méthodes delta en halicutique. Rapp. int. IFREMER, DRV-86.002 RH/Nantes, $64 \mathrm{p}$.

Paulik G. J., W. H. Baylif, 1967. A generalized computer program for the Ricker model of equilibrium yield per recruitment. J. Fish. Res. Board Can., 24, 249-259.

Pelletier D., 1990, Echantillonnage des débarquements en crićc, cstimateurs des captures et variances associces. Rapp. int, IFREMER (a paraitre). 
Pope J. G., 1972. An investigation of the accuracy of Virtual Population Analysis using Cohort Analysis. Int. Comm. Northwest Atl. Fish. Res. Bull., 9, 65-74.

Pope J. G., 1977. Estimation of fishing mortality, its precision and implications for the management of fisheries. In: J. H. Stecle, Fisheries Mathematics, Academic Press, London, 63-76.

Pope J. G., J. G. Sheperd, 1985. A comparison of various methods for tuning VPA using effort data. J. Cons. int. Explor. Mer, 42, 129-151.

Prager M. H., A. D. MacCall, 1988. Sensitivities and variances of Virtual Population Analysis as applied to the mackerel, Scomber japonicus. Can. J. Fish. Aquat. Sci., 45, 539-547.

Rivard D., 1981. Catch projections and their relation to sampling error of rescarch surveys. In: Doubleday W. G., D. Rivard, 1981. Bottom trawl survcys. Can. Spec. Publ. Fish. Aquat. Sci., 58, 273 p.

Rivard D., 1982. APL programs for stock assessment (revised). Can. Tech. Rep. Fish. Aquat. Sci., 1091, 146 p.
Rivard D., 1983. Effects of systematic, analytical, and sampling errors on catch estimates: a sensitivity analysis. In: Doubleday W. G., D. Rivard, 1983. Sampling commercial catches of marine fish and invertcbrates. Can Spec. Publ. Fish. Aquat. Sci., 66, 290 p.

Saila S. B., E. Lorda, H. A. Walker, 1985. The analysis of parameter error propagation in simple fishery models. Mar. Resource Econ., 1, 235-247.

Sampson D. B., 1987. Variance estimators for Virtual Population Analysis. J. Cons. Int. Explor. Mer, 43, 149-158.

Sampson D. B., 1988. The stability of Virtual Population Analysis cohort size estimates. J. Cons. int. Explor. Mer, 44, $135 \cdot 142$.

Thompson W. F., F. H. Bell, 1934, Biological statistics of the Pacific halibut fishery. 2. Effect of changes in inten. sity upon total yield and yield per unit of gear. Rep. Int. Fish. (Pacific IIalibut) Comm.. 8, 49 p.

Vetter E. F., 1988. Estimation of natural mortality in fish stocks: a revicw. Fish. Bull.. 86. 25-43.

\section{APPENDIX}

Delta-method

Considering a statistic $G$, which can be expressed as a function of random variables' empirical moments $\Lambda_{1}, \ldots, \Lambda_{k}$. Since these moments converge towards mathematical moments $\lambda_{1}, \ldots, \Lambda_{k}$, it is possible to expand $G\left(\Lambda_{1}, \ldots, \Lambda_{k}\right)$ in Taylor series at the point $\left(\Lambda_{1}, \ldots, \Lambda_{k}\right)$. $\Lambda$ pplying the expectation operator, estimators of the expected value and variance of $G$ can be obtained at any order, in practice one or two.

Concerning yield per recruit, the expression given in equation (16) is expanded at the first order as:

$$
\begin{aligned}
\mathrm{Y}_{r}(\mu)=\mathrm{G}\left(c_{i}, m_{i}, f_{\mathrm{T}}, w_{i}\right)+\sum_{i}\left[\left(\frac{\hat{c} \mathrm{G}}{\partial \mathrm{C}_{i}}\right)_{c_{i}}\left(\mathrm{C}_{i}-c_{i}\right)+\left(\frac{\hat{c} \mathrm{G}}{\partial \mathrm{M}_{i}}\right)_{m_{i}}\left(\mathrm{M}_{i}-m_{i}\right)\right. & \left.+\left(\frac{\hat{c} \mathrm{G}}{\partial \mathrm{W}_{l}}\right)_{w_{i}}\left(\mathrm{~W}_{i}-w_{i}\right)\right]+\left(\frac{\hat{c} \mathrm{G}}{\partial \mathrm{F}_{\mathrm{T}}}\right)_{f_{\mathrm{T}}}\left(\mathrm{F}_{\mathrm{T}}-f_{\mathrm{T}}\right)+\mathrm{O}(1)
\end{aligned}
$$

where $c_{i}, m_{i}, f_{\mathrm{T}}, w_{i}$ are true values, unknown but estimated and variables in capitals are current values, $i . e$. stochastic variables. $O(1)$ is a term which is at most an order of $1 . \mu$ is not an estimated parameter but is chosen by the user.

Thus, variance of yield per recruit is:

$$
\operatorname{Var}\left(Y_{r}\right)=E\left(Y_{r}^{2}\right)-\left(E\left(Y_{r}\right)\right)^{2}
$$

If yield per recruit is replaced by its expansion and if biases of input parameter estimators are neglected, the following equation is obtained for the variance:

$$
\begin{aligned}
& \operatorname{Var}\left(\mathrm{Y}_{r}\right)=\sum_{i}\left[\left(\frac{\hat{c} \mathrm{G}}{\hat{c} \mathrm{C}_{i}}\right)_{c_{i}}^{2} \operatorname{Var}\left(\mathrm{C}_{i}\right)+\left(\frac{\hat{c} \mathrm{G}}{\hat{c} \mathrm{M}_{i}}\right)_{m_{i}}^{2} \operatorname{Var}\left(\mathrm{M}_{i}\right)+\left(\frac{\hat{c} \mathrm{G}}{\partial \mathrm{W}_{i}}\right)_{w_{i}}^{2} \operatorname{Var}\left(\mathrm{W}_{i}\right)\right]+\left(\frac{\hat{c} \mathrm{G}}{\partial \mathrm{F}_{\mathrm{T}}}\right)_{f_{\mathrm{T}}}^{2} \operatorname{Var}\left(\mathrm{F}_{\mathrm{T}}\right) \\
& +\sum_{i}\left[\left(\frac{\hat{c} \mathrm{G}}{\partial \mathrm{F}_{\mathrm{T}}}\right)_{f_{\mathrm{T}}}\left(\frac{\hat{c} \mathrm{G}}{\hat{c} \mathrm{C}_{i}}\right)_{c_{i}} \operatorname{Cov}\left(\mathrm{F}_{\mathrm{T}}, \mathrm{C}_{i}\right)+\left(\frac{\hat{\partial} \mathrm{G}}{\hat{c} \mathrm{~F}_{\mathrm{T}}}\right)_{f \mathrm{~T}}\left(\frac{\hat{\partial} \mathrm{G}}{\partial \mathrm{M}_{i}}\right)_{m_{i}} \operatorname{Cov}\left(\mathrm{F}_{\mathrm{T}}, \mathrm{M}_{i}\right)+\left(\frac{\hat{c} \mathrm{G}}{\hat{\partial} \mathrm{F}_{\mathrm{F}}}\right)_{f_{\mathrm{T}}}\left(\frac{\hat{c} \mathrm{G}}{\partial \mathrm{W}_{i}}\right)_{\mathrm{w}_{i}} \operatorname{Cov}\left(\mathrm{F}_{\mathrm{T}}, \mathrm{W}_{i}\right)\right] \\
& +\sum_{i j}\left[\left(\frac{\hat{\mathrm{G}}}{\hat{c} \mathrm{C}_{i}}\right)_{c_{i}}\left(\frac{\hat{c} \mathrm{G}}{\hat{c} \mathrm{M}_{j}}\right)_{m_{j}} \operatorname{Cov}\left(\mathrm{C}_{i}, \mathrm{M}_{j}\right)+\left(\frac{\hat{c} \mathrm{G}}{\hat{c} \mathrm{C}_{i}}\right)_{c_{i}}\left(\frac{\hat{c} \mathrm{G}}{\partial \mathrm{W}_{j}}\right)_{w_{j}} \operatorname{Cov}\left(\mathrm{C}_{i}, \mathrm{~W}_{j}\right)+\left(\frac{\hat{c} \mathrm{G}}{\partial \mathrm{M}_{i}}\right)_{m_{j}}\left(\frac{\hat{c} \mathrm{G}}{\partial \mathrm{W}_{j}}\right)_{w_{j}} \operatorname{Cov}\left(\mathrm{M}_{i}, \mathrm{~W}_{j}\right)\right]+O(1)
\end{aligned}
$$

\footnotetext{
${ }^{1}$ Sensitivities to $F_{\mathrm{T}}$ and $W_{i}$ were not considered for the "gain-

loss" function.
} 